\title{
A ideologia do cientificismo
}

\author{
José Leon Crochíc \\ Gustavo Martineli Massola \\ Bernardo Parodi Svartman \\ Universidade de São Paulo, Instituto de Psicologia. São Paulo, SP, Brasil
}

A área da psicologia que estuda seres humanos traz como peculiaridade o fato de o objeto estudado ser o próprio sujeito, o que levanta algumas questões para a produção científica nesta área. Uma delas é se a ciência é a única forma de se conhecer a psicologia humana, ou se a arte e a filosofia também não podem contribuir consideravelmente para esse conhecimento. Outra se refere ao caráter social desse objeto psicológico, uma vez que o ser humano não pode ser reduzido somente às suas características naturais; se isso procede, o estudo psicológico não pode ser totalmente independente da teoria da sociedade que expressa $o$ movimento desta sociedade. Essa última questão indica a necessidade da reflexão teórica que precisa considerar não somente os fatos, mas o que os determina. Considerando somente essas duas questões, tem-se que a distância do objeto que o conceito científico requer é distinta daquela própria à arte e à teoria; essas últimas necessitam de aproximação do objeto.

Ao final da década de 1960, a ciência e a tecnologia foram pensadas por Habermas (1968/1983) em seu caráter ideológico. Sem negar a contribuição da racionalidade científica e técnica para a emancipação social, destacou a invasão da esfera do quadro institucional pela lógica do agir instrumental: a linguagem, as normas, os valores seriam mediados por uma lógica externa aos sujeitos, apropriada à transformação da natureza para a sobrevivência humana, mas não ao que nomeou "quadro institucional". Isso se expressou em uma consciência tecnocrática que:

é, por um lado, "menos ideológica" que todas as ideologias anteriores; pois ela não possui a violência opaca de um ofuscamento que joga apenas com a ilusão de satisfação dos interesses. Por outro lado, a vítrea ideologia de fundo hoje dominante, que transforma a ciência em fetiche, é mais irresistível e mais abrangente do que as ideologias do tipo antigo, pois com o velamento das questões práticas, ela não somente justifica um interesse de dominação parcial de uma classe determinada e oprime a necessidade parcial de emancipação por parte de outra classe, como também atinge o interesse emancipatório da espécie humana, como tal. (p. 335)
Com a ocultação das "questões práticas", isto é, políticas, a sociedade pode se reproduzir com os interesses daqueles que detêm não só o poder econômico, mas também político - esse último com a aparência do saber científico-administrativo. A ciência se torna, involuntariamente, reacionária. Tal visão cientificista implica pensar todas as esferas da realidade por meio de categorias lógicas, sistemáticas: os conflitos individuais são reduzidos a problemas psicológicos; as contradições sociais, a imperfeições lógicas do sistema; a política é reduzida a questões administrativas. Não é casual que nas eleições para os cargos executivos tenham preferência de parcela grande da população os políticos que apresentam a imagem de bons administradores; o que importa, nos dias que correm, não é mais o conhecimento, a sabedoria, mas o como fazer, o método, o procedimento. Nas palavras de Horkheimer e Adorno (1947/1985): "O que importa não é aquela satisfação que, para os homens, se chama 'verdade', mas a 'operation', o procedimento eficaz". (p. 20)A racionalidade do método científico e a lógica dedutiva seriam a solução para todos os problemas. No entanto, segundo Horkheimer e Adorno (1947/1985), tanto a lógica subjetiva quanto o domínio dos fatos, por eliminarem a distinção e a relação entre sujeito e objeto, recaem na esfera do mito, que pretendiam superar: a lógica do sujeito, pois reduz o que é objeto às categorias formais do pensamento, estabelecidas pelas experiências históricas do controle humano sobre a natureza, perdendo assim a "crítica da razão pura" delimitada por Kant; o culto aos fatos, que mais ilusório do que o pensamento que pretende negar, ignora que o próprio método científico é produto do sujeito, e, por isso, somente objetivo no que diz respeito à apropriação dos objetos conforme os interesses humanos. Se o conhecimento se produz na relação entre sujeito e objeto, a negação de cada um dos polos converte-se em falso conhecimento. Conforme Horkheimer e Adorno (1947/1985), ao se negar o objeto, há a presença da paranoia, um pensar que não é delimitado pelos objetos; ao se negar o sujeito do conhecimento, resigna-se à duplicação da realidade, abdicando-se do pensamento:

A profundidade interna do sujeito não consiste em nada mais senão a delicadeza e a riqueza do mundo da percepção externa. Quando o entrelaça- 
mento é rompido, o ego se petrifica. Quando ele se esgota, no registro positivista de dados, sem nada dar ele próprio, se reduz a um simples ponto; e se ele, idealisticamente, projeta o mundo a partir da origem insondável de si mesmo, se esgota numa obstinada repetição. Nos dois casos, ele sacrifica o espírito. (p. 176)

A ciência e a técnica são produtos das relações históricas entre os homens e o mundo. Nesse sentido, devem ser entendidas pela mediação que a totalidade social estabelece. São, como defende Adorno (1972/1983), simultaneamente força produtiva e relações de produção: auxiliam no progresso que tem como objetivo superar a miséria material e intelectual, e também são responsáveis pela reprodução da desigualdade social, na medida em que sua pretensa neutralidade serve aos interesses sociais mais fortes. Dessa forma, não cabe negar a importância do saber científico e técnico, tampouco ignorar que servem igualmente à reprodução da miséria social.

Essa racionalidade científica e técnica, em nossos dias, está fortalecida; na Academia isso é esperado, mas mesmo assim deve-se perguntar se ela não restringe o saber em vez de ampliá-lo. Como já apontava Adorno (1969/1993), essa racionalidade que termina por hipostasiar a separação entre sujeito e objeto revela-se na maneira pela qual o método pré-definido, imposto com indiferença em relação a seu objeto, impede a observação de que o dado colhido é mediado socialmente. No caso da psicologia, isso redunda em duas tendências: as expressões psicológicas conformadas pelo método são tratadas como se tivessem início em si mesmas, como dados puros, ou então os estudos impõem uma organização e classificação de fenômenos psicológicos um tanto arbitrária, revelando a perda de relação com o objeto e a tendência de projeção do sujeito à sua revelia. Ainda que o processo de socialização condicione uma coisificação do homem que permite seu estudo por meio de métodos assim conformados (escalas e questionários, por exemplo), a questão que se impõe é justamente como a pesquisa apoiará uma discussão que não se limite a afirmar tal estado de coisas, sustentando a crítica à coisificação do espírito.

A ênfase na pesquisa científica, que tem sua importância sobretudo em uma universidade, já transpôs os limites dessa e já é oferecida no Ensino Médio e até na pré-escola por meio do ensino de métodos de observação. O ensino anterior à universidade que tinha um caráter geral e visava a socialização para além de uma forma específica de produção de saber, permitindo em alguma medida tanto a adaptação à totalidade social quanto sua crítica, pode continuar a manter esse caráter, mas com um método uniforme, padronizado, fruto da aplicação da própria racionalidade científica à administração centralizada da formação escolar de grandes contingentes populacionais. Por outro lado, na Academia o conhecimento apreciado é proveniente de uma produção científica que deve se submeter a métodos de criação abstratos que se expressam muitas vezes em regras de publicação definidas por grandes editoras internacionais, sendo assim cerceadas outras possibilidades de expressão que não se ajustem adequadamente a essas normas, o que restringe a expressão e molda um pensamento que torna-se também delimitado.

Quando pensamos em grandes escolas psicológicas como o behaviorismo, o humanismo e a psicanálise, constata-se que foram constituídas não somente com dados provenientes da ciência, mas também da filosofia, da literatura e de outras disciplinas como a sociologia e a antropologia. A desvalorização e, em muitos casos, a mera recusa da publicação de ensaios por periódicos na área da psicologia indicam já essa redução do conhecimento a sua forma científica e algumas de suas consequências. $\mathrm{O}$ ensaio apresenta semelhanças e distinções de um texto artístico e de um artigo científico: assemelha-se ao texto artístico, pois re(a)presenta o objeto a ser estudado que procura ser analisado por meio da proximidade do sujeito em relação a ele; distingue-se, pois o objeto re(a)presentado pela $m i$ mesis não é gerado pela fantasia; e assemelha-se ao texto científico pois se cerca de dados empíricos e/ou de teorias, mas não tenta proceder do mais simples ao mais complexo, não divide o objeto de análise e não tem um método de análise sistemático a ser generalizável a outros estudos. Os principais proponentes das grandes escolas psicológicas lançaram mão com frequência dessa forma literária, especialmente em momentos nos quais a transformação da relação entre a empiria e o todo social apontava os limites de formas anteriores de interpretação e exigia saltos teóricos inacessíveis por meio de uma estrita indução empírica. Dessa forma, ao fazer a crítica ao cientificismo atual, não se quer defender formas de conhecimento atreladas ao mítico, ao religioso ou à mera superstição, mas indicar que a arte também deve ter lugar como forma de conhecimento numa ciência como a psicologia e que a reflexão teórica não deveria estar ausente de nenhuma publicação; isso é, essa nunca deveria ser reduzida a relato de pesquisa.

Ao fazer a crítica da restrição da produção científica ao método científico ou à teoria da técnica, não se quer negar a importância dessas, mas chamar a atenção sobre duas outras formas de saber fundamentais para todas as disciplinas científicas, especialmente para as humanas, como a psicologia: a arte e a reflexão teórica. A arte, ao contrário do conceito científico que pede pelo distanciamento do objeto, exige a aproximação para que este seja reapresentado, e não pode prescindir da $m i$ mesis. Na área das ciências humanas, sobretudo na psicologia, é difícil negar a importância da literatura para pensar como a subjetividade se constitui historicamente na sua relação com diferentes formas sociais, ou contraditoriamente, constituir uma psicologia universal, como Adorno (1958/1983) percebe a obra de Dostoiévski. Já a teoria, que não se deve reduzir à prática ou aos fatos, não tem uma relação imediata com esses. Aos que entendem que a teoria pode e deve ser comprovada ou não pelos fatos, deve-se responder que esses últimos são delimitados à época e lugar onde ocorrem, enquanto a teoria, por se 
pautar pela história da transformação desses fatos, não pode ser reduzida a eles. A teoria pode indicar tendências de movimentos dos objetos sobre os quais reflete: uma boa análise teórica de como tal ou qual fenômeno ocorreu e continua a ocorrer permite delinear tendências, que se confirmarão caso as determinações desse fenômeno se mantiverem. Nesse sentido, quando tem seus dados refletidos, a ciência pode alterar politicamente o que estuda, e quando isso não ocorre, pode contribuir, como já ressaltamos, com sua manutenção.

\section{Referências}

Adorno, T. W. (1983). Introdução à controvérsia sobre o Positivismo na sociologia alemã. In W. Benjamin, M. Horkheimer, T. W. Adorno \& J. Habermas, Textos escolhidos (W. L. Maar, trad., pp. 209-257). São Paulo, SP: Abril Cultural. (Trabalho original publicado em 1972)

Adorno, T. W. (1983). Posição do narrador no romance contemporâneo. In W. Benjamin, M. Horkheimer, T. W. Adorno \& J. Habermas, Textos escolhidos (W. L. Maar, trad., pp. 269-273). São Paulo, SP: Abril Cultural. (Trabalho original publicado em 1958)
Adorno, T. W. (1993). Sobre sujeto y objeto. In Consignas (Rámon Bilbao, trad., pp. 143-158). Buenos Aires: Amorrotu. (Trabalho original publicado em 1969)

Habermas, J. (1983). Técnica e ciência enquanto ideologia. In W. Benjamin, M. Horkheimer, T. W. Adorno \& J. Habermas, Textos escolhidos (Z. Loparic \& A. M. A. C. Loparic, trad., pp. 313-343). São Paulo, SP: Abril Cultural. (Trabalho original publicado em 1968)

Horkheimer, M., \& Adorno, T. W. (1985). Dialética do esclarecimento (G. de Almeida, trad.). Rio de Janeiro, RJ: Jorge Zahar. (Trabalho original publicado em 1944/1947) 